\title{
Study on Cultural Heritage Protection of Minority Sports Culture
}

\author{
Bo Xiao ${ }^{1}$ \\ ${ }^{1}$ Sichuan Minzu College, Kangding, Sichuan, 626001
}

KEYWORDS: Cultural Heritage; Protection; National Minority Sports

\begin{abstract}
Culture is a continuation of ethnic blood, human shared spiritual home, the protection of cultural heritage has become the focus of the world's precious heritage topic of intangible cultural heritage is non-renewable, it is the crystallization of human wisdom, carrying the national spirit of the people of the world and we will witness the rise and fall of the development and evolution of society, and describe the exciting chapter in the history of mankind. Sports intangible cultural heritage of other cultural forms do not have dual characteristics, not only in the construction of cultural power and culture in the process play a huge role, but also to promote the various regions of sports for development. In this paper, the various aspects of traditional minority sports cultural heritage protection studies, trying to establish the principle of protection as the foundation, put forward specific protection measures.
\end{abstract}

\section{Introduction}

Conduct research aspects, trying to establish the principle of protection as the foundation, put forward specific protection measures. Chinese national sports, the ancestors created and accumulated in traditional culture, fully embodies the cultural values of all nationalities and shared aesthetic ideal in the long history, it has both associated with sports competitions program, production equipment, rules of the game sports and other physical content, but also the social characteristics of each nation's economic life, rituals, customs, traditions and cultural phenomenon closely related to the history and culture, is a "living cultural legacy," which embodies the vitality and creativity of the Chinese nation force, all ethnic wisdom, but also treasures of mankind. The protection of national traditional sports heritage, both cultural heritage and the basis of various ethnic development, and also to maintain the uniqueness of Chinese culture and the revival of an important part of Chinese culture.

\section{Characteristics of National Traditional Sports Culture}

National Traditional Sports Culture is a "Living human heritage", with a living state, regional, folk, community, and other features.

Live the basic characteristics of a living state of non-material cultural heritage. "This 'live', in essence it is manifested as a soul. The soul is the creation of her heritage and the nation (community) together into their own in the long-term struggle and the creation of a unique national spirit and national psychology is epitomized by common beliefs and follow the core values. "The intangible cultural heritage of legends, expression, performers and traditional craft skills of the operator, non-material cultural heritage" living "culture created by the body, most has initiative, in "living" the core of culture. They are at different times, different regions, different sessions expressed or scene, performances and skills to operate, will be played, is a new creation. National Traditional Sports culture as a kind of "physical culture", its meaning is the performance by the human body's 
activities and to convey, more intuitive, such as martial arts emphasize the "heart and Italy, Italy, and gas combined, gas and combined force; shoulder and hips together, elbows and knees together, hands and feet together, "or" triple inner and outer triple "is actually requested by the inner heart, mind, external air to the limbs, body parts are achieve mutual coordination.

Since the beginning of the Spring and Autumn Regional to smallholders as the main single agricultural economic structure of China's evolving, rhythmic agricultural production cycle for a large number of farmers engaged in household sideline and handicraft leisure time, as a result, the formation of ten million economic structure based on self-sufficient economic units. National Traditional Sports Culture in this economy based on the formation of a strong regional. Form the basis of the Chinese traditional sport is mainly agricultural, nomadic and hunting lifestyle categories, ethnic groups in the same or similar geographical living space, in other production methods and lifestyles are always similar, the most direct and cultural exchange frequently, the formation of a special regional interest in life. Some traditional sports events of various ethnic groups having similarity in form, but different regions have different names, content and origin of the legend.

The main characteristic of Chinese ancient folk social and political structure is the formation of a complete set of kinship ties patriarchal system. Patriarchal system is kinship and ancestral worship from primitive society clan system under developed, due to the characteristics of the agricultural economy of the decision. In the long Chinese feudal society, stressing that "Restraining Commerce", "founded on agriculture," Ethics and Political Ethics blood relationship between the imperial family-oriented highly unified feudal ethics relationship entrenched. Consequently, many national traditional sports activities are not daily workout or competition, but by the throttle periodically agriculture ancestor worship and pray Folk rites, such as the Chinese New Year lion dance, dragon boat racing Dragon Boat Festival.

\section{Value of Sports Culture of Ethnic Minorities}

Minority Games of cultural heritage carries a rich history, the era of the past handed down a wealth of history, we can recognize from a living state, to understand the history. In sports heritage, for example, whatever the project, there are always specific historical conditions which produces a total history with specific characteristics of the times, through these projects, we can understand the level of development of production of a particular historical period, lifestyle and social structure of the organization, the relationship between people, moral customs and ideological taboos.

Minority Games cultural heritage contains a wealth of cultural resources, vivid record of outstanding wisdom and intelligence of different ethnic groups, it is to recognize minority cultures living fossil. Minority Games cultural heritage, his mouth deep essence of traditional culture of ethnic minorities, original, reflect the cultural characteristics of ethnic minorities, emits minority way of thinking, aesthetic way of development, reflecting the unique minority traces of history and culture, showing a distinct cultural values.

Famous French writer Victor Hugo in the French Revolution comes to how to deal with the historical heritage, the firm had said: No matter how much the owners have the right to not allow these immodest, blinded by the owners of destroyed historic monuments; they are despicable believers, even stupid to even know that they are not barbarians, A building, there are two things, one purpose, the second is the United States, use of a building belongs to the owner, and the United States belong to the people, Destroy their buildings, is beyond his right to Hugo mankind, historical perspective emphasizes the aesthetic value of the cultural heritage belongs to the whole world. The aesthetic value of the cultural heritage of Hugo emphasized, also fully applicable to the evaluation 
of the aesthetic value of the cultural heritage of minority nationalities, the idea still has a strong practical significance today.

Minority Games educational value of cultural heritage, on the one hand that contains a wealth of historical and cultural knowledge, a lot of scientific content, there are many important ideas and concepts, it is worth using this wealth of knowledge to carry out school education and social education. Another aspect is that the minority to make physical education has become an important aspect of physical education, making education Minority Games cultural heritage protection, an important way of inheritance. This requires the active set about minority sports courses taught at various schools or school sports in Canada provided the content of minority sports, so that the majority of minority students to understand the sport, recognizing its value; carried out in the community about the value and importance of the cultural heritage of minority sports publicity and education, pay attention to the formation of traditional sports of minority social atmosphere. Minority Games in order to better enable the sport to cultural heritage through the effective protection and the role of education.

\section{Sports Culture Protection of Minority}

The basic principles for the protection of minority sports culture have been identified, the next step is based on these principles put forward countermeasures, of course, we are still here propose appropriate countermeasures according to the actual problem AGIL model minority sports cultural heritage protection and the presence of the above analysis. First, mobilize social forces to actively participate. Protection and Inheritance of National Traditional Sports Culture is not just a matter of concern in some professionals, it should be a matter of concern throughout the nation. The protection of traditional culture and inheritance must launch a full enthusiasm and initiative to encourage the masses to actively participate in the protection of minority sports cultural heritage in the past, mobilize the whole society to carry out advocacy for minority sports culture and heritage, so that traditional national sports culture protection more effective and successful. You can also use the school premises, the traditional sports cultural history and traditional ethnic minority sports introduced into school curricula, strengthening the heritage and the development of minority sports culture. Government, as the protection of intangible cultural body for the protection of national sports culture plays a vital role. If there is no government policy support, national sports culture will be forever, marginalized, government-led mechanism means that the government bears the responsibility to protect and support the National Traditional Sports Culture. In practice, the protection process, on the one hand the government should take protective strategy, excavating, collecting, sorting, and invest the necessary funds on a special study conducted rescue protection, especially the protection of outstanding projects with ethnic traditional sports culture, stunts, successor and masterpieces; with audio, text, or hypertext form will object statically or dynamically reproduce or show it. On the other hand the government should do the publicity and education, so that the majority of people understand the value and importance of minority sports culture, improve their social awareness. Local governments may hold some ethnic characteristics of national sports organizations on local resources, the consolidation of the mass base of minority sports culture in the region. Of course, the Government should also provide funds for protection of minority sports culture of investment, the establishment of special funds system. Due to the wide dispersion of our national distribution and, most remote and complex environment, the establishment of specialized institutions for the protection of national culture and sports studies, a clear division of labor, organization of scientific research, it is very necessary. On the one hand, to establish some funded by the state to protect the cultural heritage of minority sports stadium project, in the form of the 
original museum preserved played museums, cultural centers, libraries and other cultural institutions in minority sports culture promotion and education. On the other hand, we want to set up a reasonable and effective physical culture teams, Implementation collaborates special combination of protected mode. In terms of professional researchers, should do the work team building and part of the full use of existing research results of traditional ethnic sports culture, research and academic institutions play in Kochi scholar role, but there are also a part of this organization aspects of professional knowledge about the grassroots level, full-time study to investigate minority sports culture and practice of protection. Finally, establish a sound legal system. Improve laws and regulations to protect the cultural heritage of minority sports are not only the national government for the protection of traditional sports culture and constraints of a specification, but also for the protection of Traditional Ethnic Sports Culture provided political and ideological guidance. In practical level, standardized education and behavior will improve laws and regulations on the whole nation of people play a role in guiding nature. To further improve and perfect the relevant laws and regulations and policies, developing an overall plan to protect minority sports culture, and strengthen legislation to protect the traditional culture of minority sports, physical culture and clarify the legal status of ethnic minorities, so that there are laws must be strictly enforced.

\section{Conclusion}

For minority sports culture in different regions, we should be carried out according to the current situation and condition of the traditional sports culture of economic development in different regions around the grading pilot demonstration of progress, and actively share experiences and learn from. The good experience to promote the open, the lessons learned and issues into the open, to avoid detours. In the pilot to promote the process, to make minority sports culture creator, owner and successor to see prospects tasted the sweetness, to get the actual identity and interest in these ancient traditional sports culture and voluntarily return to these guard and carry forward ancient culture up position, so that a culture has been the survival and development of space and soil.

\section{Acknowledgements}

Proj.: Study on the Development and Innovation Strategy of Modern Kang-pa Sports Culture Dissemination." Key Project of Humanities and Social Sciences of Sichuan Provincial Education Department in 2015

Project NO.: 15SA0138

\section{Reference:}

[1] Ni Yike, Hu Xiaoming. National Traditional Sports Cultural Heritage Protection [J]. Physical Sciences, 2006,26 (8): 66-70.

[2] Liu Kuili. China Intangible Cultural Heritage Protection under The Background of Globalization [J]. Henan Social Sciences, 2007 (1): 25-34.

[3] Ma Hui, Fang Zheng. Minority Traditional Physical Culture [J]. Ningxia University (Humanities and Social Sciences), 2004 (6): 107-115.

[4] Xu Xiaojun, Zhang Bichun. Rural And Indigenous Culture, Modern Risks and Survival Crisis [J]. Mao Zedong and Deng Xiaoping Theory, 2007 (10): 61-66.

[5] Chen Qingyun. Intangible Cultural Heritage Study [J]. Legal Protection Of The Central 
University For Nationalities, 2006 (1): 40-44. 